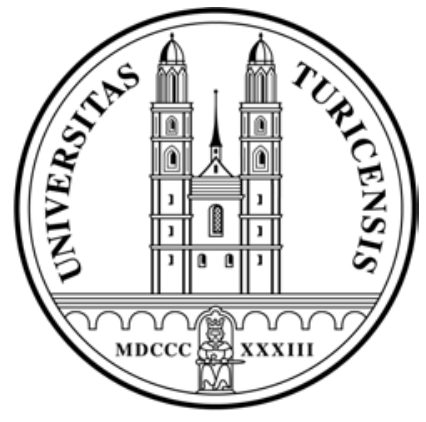

Institute for Empirical Research in Economics

University of Zurich

Working Paper Series

ISSN 1424-0459

Working Paper No. 249

Myopic Loss Aversion Revisited: The Effect of Probability Distortions in Choice Under Risk

Pavlo Blavatskyy and Ganna Pogrebna

June 2005 


\title{
MYOPIC LOSS AVERSION REVISITED: THE EFFECT OF PROBABILITY DISTORTIONS IN CHOICE UNDER RISK*
}

June 2005

\section{Pavlo Blavatskyy ${ }^{1}$ and Ganna Pogrebna ${ }^{2}$}

\begin{abstract}
When the performance of a risky asset is frequently assessed, the probability of detecting a loss is high, which averts the loss averse investors. This effect is known as myopic loss aversion (MLA). This paper reexamines several recent experimental studies documenting the existence of MLA. A closer look at the experimental data reveals that the effect of MLA is largely neutralized by the overweighting of small probabilities and the underweighting of moderate and high probabilities. Remarkably, the two effects exactly balance each other out for conventional parameterizations of cumulative prospect theory. MLA alone cannot explain the observed investment decisions.
\end{abstract}

Key words: myopic loss aversion, experiment, probability weight, prospect theory JEL Classification codes: D81, C91, D14

\footnotetext{
* We are grateful to Uri Gneezy, Jan Potters, Michael Haigh and John List, who generously provided their experimental data.

${ }^{1}$ Corresponding author, Institute for Empirical Research in Economics, University of Zurich, Winterthurerstrasse 30, CH-8006 Zurich, Switzerland, tel.: +41(0)446343586, fax: +41(0)446344978, e-mail: pavlo.blavatskyy@iew.unizh.ch

${ }^{2}$ University of Innsbruck, Department of Economics, Institute of Public Finance, Universitätstrasse 15/4, A - 6020 Innsbruck, Austria, tel.: +43 (0)5125077148, email: ganna.pogrebna@uibk.ac.at
} 


\section{Myopic Loss Aversion Revisited: The Effect of Probability Distortions in Choice under Risk}

\section{Introduction}

Benartzi and Thaler [1995] proposed a new behavioral theory-myopic loss aversion (MLA) as an explanation for the equity premium puzzle [Mehra and Prescott, 1985]. MLA combines two behavioral concepts - loss aversion and mental accounting. Loss aversion refers to the observation that the aggravation from losing a sum of money often exceeds the pleasure of gaining the same amount of money [Kahneman and Tversky, 1979]. Mental accounting refers to the implicit methods that individuals use to evaluate the consequences of their decisions [Kahneman and Tversky, 1984]. The aspect of mental accounting that is important for MLA is how often individuals evaluate financial outcomes [Benartzi and Thaler, 1995]. When framing outcomes narrowly, an individual evaluates losses and gains more frequently [Thaler et al., 1997].

For lotteries with positive expected value and a possibility of a loss, high frequency evaluation can lead to a greater dissatisfaction [Haigh and List, 2005]. When the performance of such lotteries is frequently assessed, the losses are more likely to be detected. Since the aggravation from losses exceeds the pleasure from gains, this leads to a greater dissatisfaction than when the same lotteries are evaluated infrequently. Thaler et al. [1997], Gneezy and Potters [1997], Gneezy et al. [2003] and Haigh and List [2005] provide experimental evidence supporting this implication of MLA. Individuals appear to invest significantly higher amounts in a risky lottery when its performance is assessed over a longer time period.

This paper reexamines the experimental data documenting the presence of MLA. In particular, we take a closer look at the experimental results of Gneezy and 
Potters [1997] and Haigh and List [2005], who generously provided their data. Gneezy and Potters [1997] as well as Haigh and List [2005] conducted a conventional laboratory experiment with a student subject pool. In addition, Haigh and List [2005] conducted an "artefactual field experiment" [Harrison and List, 2004] i.e. an experiment with a nonstandard subject pool (professional traders).

In the experiments of Gneezy and Potters [1997] and Haigh and List [2005] the subjects are asked to invest a fraction of their initial endowment into a risky lottery. The majority of subjects invest some intermediate amount and only few subjects do not invest at all or invest their entire endowment. This result holds in the laboratory as well as in the field experimental setting and it also holds for both treatments: when the risky lottery is evaluated with high and low frequency.

MLA alone cannot explain this observation. Since the initial endowment is small (around one U.S. dollar) the calibration theorem of Rabin [2000] can be invoked to argue that the utility function is linear (with a kink at the reference point to capture the loss aversion). An individual with such utility function invests an intermediate amount into a risky lottery if and only if he or she is exactly indifferent between investing and not investing. This allows us to identify the index of loss aversion [Köbberling and Wakker, 2005] for the majority of subjects (who do not invest zero or $100 \%$ of their initial endowment). In the treatment, when lottery is evaluated with high frequency, the majority of subjects have a lower index of loss aversion than in the treatment, when lottery is evaluated with low frequency. However, this contradicts to the random assignment of subjects to both treatments.

The above argument does not depend on the utility function being exactly piecewise linear. For example, it also holds true for the stylized value function of the 
cumulative prospect theory [Tversky and Kahneman, 1992]. We demonstrate that the observed investment decisions can be rationalized if the subjects weight probabilities in a non-linear manner. Apparently, the effect of MLA is largely neutralized by a non-linear probability weighting in choice under risk. The probability of a loss is smaller when the lottery is evaluated infrequently. However, when individuals overweight small probabilities [Tversky and Kahneman, 1992], this can cause a greater dissatisfaction with the lottery.

Langer and Weber [2005] recently demonstrated that the effect of MLA can be largely neutralized by the diminishing sensitivity to gains and losses, which is captured by the S-shaped value function of prospect theory. For specific lotteries with a low probability of a high loss (e.g. investment in a low rated junk bond), myopia does not decrease but increase the attractiveness of repeated investment. Langer and Weber [2005] support this conjecture with experimental evidence. They also take into account the effect of non-linear probability weighting. However, in contrast with this paper, Langer and Weber [2005] do not explore its interrelation with the effect of MLA for different parameterizations of probability weighting functions.

The remainder of this paper is organized as follows. The next section reexamines the experimental results of Gneezy and Potters [1997] and Haigh and List [2005] and demonstrates that MLA alone cannot rationalize the observed investment decisions. Section III demonstrates that the experimental results can be explained by a combination of non-linear probability weighting and MLA, with the two effects working in the opposite directions. Section IV illustrates the effects of non-linear probability weighting and MLA using a famous example due to Samuelson [1963]. Section V concludes. 


\section{Reexamination of Experimental Evidence}

Gneezy and Potters [1997] and Haigh and List [2005] use a nearly identical experimental design to test for the presence of MLA. In both experiments, the subjects choose how much of their initial endowment they want to invest in a risky lottery. If amount $x$ is invested, the lottery yields $-x$ with probability $2 / 3$ and $2.5 x$ with probability $1 / 3$. The subjects are randomly assigned to one of the two experimental treatments [Gneezy and Potters, 1997; Haigh and List, 2005]. In treatment H, the lottery is evaluated with high frequency. The subjects make investment decisions in 9 rounds. In rounds 2-9 the subjects observe the outcome of the lottery realized in the previous round. In treatment $\mathrm{L}$, the lottery is evaluated with low frequency. The subjects make investment decisions only in round $t \in\{1,4,7\}$. The level of investment chosen in round $t$ remains constant in rounds $t, t+1$ and $t+2$. In rounds 4 and 7 the subjects observe the cumulative outcome of the lottery realized in the previous three rounds. In both treatments the subjects receive a new initial endowment at the beginning of every period that does not depend on the cumulative earnings in the previous rounds.

\section{[Insert Table I and Table II here]}

Tables I and II classify the subjects in the experiments of Gneezy and Potters [1997] and Haigh and List [2005]. Classification is based on the investment decisions of the subjects. Table I summarizes investment decisions in treatment $\mathrm{H}$. The majority of subjects invest an intermediate fraction (1\%-99\%) of their endowment. About $15 \%$ of subjects do not invest at all and about $15 \%-20 \%$ of subjects invest $100 \%$ of their

endowment. Table II summarizes investment decisions in treatment L. The majority of subjects invest an intermediate fraction (1\%-99\%) of their endowment. There are no 
subjects who abstain from investing. The percentage of subjects who invest $100 \%$ of their endowment does not exceed $36 \%$.

When we compare Tables I and II, the percentage of subjects who do not invest at all is higher when lottery is evaluated with high frequency. The percentage of subjects who invest their whole endowment is higher when lottery is evaluated with low frequency. These two observations are consistent with the hypothesis of MLA. However, MLA cannot explain the fact that the majority of subjects invest an intermediate fraction of their endowment in both treatments.

The initial endowment in the experiment of Gneezy and Potters [1997] was 2 Dutch guilders (around 1.2 U.S. dollar). The initial endowment in the experiment of Haigh and List [2005] was 1 U.S. dollar for students and 4 U.S. dollars for professional traders. For such small stakes the utility function over money can be assumed to be linear with a kink at zero to capture the effect of loss aversion [Benartzi and Thaler, 1995]. Rabin [2000] proves a calibration theorem that even a moderate curvature of the utility function over small stakes implies implausible risk aversion over large outcomes.

Consider an individual with a piecewise linear utility function and the index of loss aversion $\lambda>1$ [Köbberling and Wakker, 2005]. The individual weighs losses relative to gains at a rate of $\lambda$ and obtains utility $2.5 \cdot x / 3-\lambda \cdot x \cdot 2 / 3=x \cdot(1.25-\lambda) \cdot 2 / 3$ from investing amount $x$ into the risky lottery for one period. Therefore, in treatment $\mathrm{H}$, the individual invests zero when $\lambda>1.25$, invests $100 \%$ of the initial endowment when $\lambda<1.25$ and invests any fraction of the initial endowment when $\lambda=1.25$ i.e. when he or she is exactly indifferent between investing and not investing. Comparing this theoretical 
prediction with the actual investment strategies summarized in Table I, we conclude that the majority of subjects in treatment $\mathrm{H}$ have the index of loss aversion $\lambda=1.25$.

In treatment $\mathrm{L}$, the individual evaluates the combined outcome of the lottery that is accumulated during three consecutive periods. The individual obtains utility $7.5 \cdot x / 27+4 \cdot x \cdot 6 / 27+0.5 \cdot x \cdot 12 / 27-\lambda \cdot 3 \cdot x \cdot 8 / 27=x \cdot(1.56-\lambda) \cdot 8 / 9$ from investing amount $x$ into the risky lottery for three periods. Therefore, in treatment $\mathrm{L}$, the individual invests zero when $\lambda>1.56$, invests $100 \%$ of the initial endowment when $\lambda<1.56$ and invests any fraction of the initial endowment when $\lambda=1.56$. Comparing this theoretical prediction with the actual investment strategies summarized in Table II, we conclude that the majority of subjects in treatment $\mathrm{L}$ have the index of loss aversion $\lambda=1.56$.

As usual in the experimental practice, the subjects have been assigned to both treatments in a random manner. Therefore, one can reasonably expect that the majority of subjects have the same index of loss aversion in both treatments. However, MLA implies that the majority of subjects have a higher index of loss aversion in treatment L. This paradoxical result does not depend on the utility function being precisely piecewise linear. Tversky and Kahneman [1992] argued that the utility function over monetary outcomes can be sufficiently accurately characterized by the functional form $u(x)=x^{\alpha}$ if $x \geq 0$ and $u(x)=-\lambda \cdot(-x)^{\beta}$ if $x<0$, where $\lambda>1$ is the index of loss aversion and $\alpha=\beta=0.88$. An individual with such utility function obtains utility $(2.5 \cdot x)^{\alpha} / 3-\lambda \cdot x^{\beta} \cdot 2 / 3 \approx x^{0.88} \cdot(1.12-\lambda) \cdot 2 / 3$ from investing amount $x$ into the risky lottery for one period. The same individual obtains utility $(7.5 \cdot x)^{\alpha} / 27+(4 \cdot x)^{\alpha} \cdot 6 / 27+(0.5 \cdot x)^{\alpha} \cdot 12 / 27-\lambda \cdot(3 \cdot x)^{\alpha} \cdot 8 / 27 \approx x^{0.88} \cdot(1.56-\lambda) \cdot 21 / 27$ from investing amount $x$ into the risky lottery for three periods. Thus, for Tversky and 
Kahneman [1992] utility function, the majority of subjects must have the index of loss aversion $\lambda \approx 1.12$ in treatment $\mathrm{H}$ and $\lambda \approx 1.56$ in treatment L. Again, this is at odds with the random assignment of subjects to both treatments.

Suppose that the majority of subjects in treatment $\mathrm{L}$ are indeed characterized by the index of loss aversion $\lambda=1.56$. If the subjects in treatment $H$ have been recruited from the same population as the subjects in treatment L, the majority of them should also have the index of loss aversion $\lambda=1.56$. However, in this case the majority of subjects in treatment $\mathrm{H}$ should invest exactly zero in the risky lottery. We do not observe such behavior in the actual investment decisions (Table I). Similarly, if the majority of subjects in treatment $\mathrm{H}$ have the index of loss aversion $\lambda=1.25$, this should be also true for the majority of subjects in treatment $\mathrm{L}$ who are recruited from the same population. However, in this case the majority of subjects in treatment L should invest $100 \%$ of their endowment in the risky lottery. This is not what we observe in the actual investment strategies (Table II). To summarize, MLA does not explain how Tables I and II can be reconciled with each other.

\section{The Role of Non-linear Probability Weighting}

An overwhelming empirical evidence suggests that individuals do not perceive probabilities linearly, when they choose between risky prospects [Bleichrodt and Pinto, 2000; Abdellaoui, 2000]. Instead, individuals make decisions as if they overweight small probabilities (unlikely events) and underweight moderate and high probabilities [Kahneman and Tversky, 1979]. One way to model such non-linear probability distortions is through an inverse S-shaped probability weighting function of cumulative prospect theory [Tversky and Kahneman, 1992]. 
Non-linear probability weighting has immediate consequences for MLA. When risky asset is monitored with high frequency, the objective probability of detecting a loss is high. However, an individual underweighting high probabilities does not perceive the chance of a loss as high as its objective probability is. Hence, such an individual finds investing in the risky lottery more attractive (compared to an individual who does not distort probabilities). When risky asset is monitored with low frequency, the objective probability of detecting a loss is low. However, an individual overweighting low probabilities does not perceive the chance of a loss as low as its objective probability is. Hence, such an individual finds investing in the risky lottery less attractive. Obviously, non-linear probability weighting has an opposite effect to the one predicted by MLA.

It is important to explore the implications of MLA when people distort probability information in a non-linear manner. We assume that an individual has a piecewise linear utility function $u(x)=x$ if $x \geq 0$ and $u(x)=\lambda x$ if $x<0$ [Thaler et al., 1997]. The calibration theorem of Rabin [2000] can be invoked to justify this assumption. We model non-linear probability distortions through the probability weighting functions $w_{+}(p)=p^{\gamma} /\left(p^{\gamma}+(1-p)^{\gamma}\right)^{1 / \gamma}$ and $w_{-}(p)=p^{\delta} /\left(p^{\delta}+(1-p)^{\delta}\right)^{1 / \delta}$ of cumulative prospect theory [Tversky and Kahneman, 1992]. The coefficients $\gamma$ and $\delta$ must be positive and smaller than one to capture the overweighting of small probabilities and the underweighting of moderate and high probabilities. The case when $\gamma=\delta=1$ denotes the absence of probability distortions, which we have considered in the previous section.

Consider again the risky lottery used in the experiments of Gneezy and Potters [1997] and Haigh and List [2005]. With non-linear probability weighting, an individual obtains utility $2.5 \cdot x \cdot w_{+}(1 / 3)-\lambda \cdot x \cdot w_{-}(2 / 3)$ from investing amount $x$ into the risky 
lottery for one period. The individual is indifferent between investing and not investing if and only if his or her index of loss aversion is

$$
\lambda=2.5 w_{+}(1 / 3) / w_{-}(2 / 3)
$$

According to cumulative prospect theory, the same individual obtains utility $3.5 \cdot x \cdot w_{+}(1 / 27)+3.5 \cdot x \cdot w_{+}(7 / 27)+0.5 \cdot x \cdot w_{+}(19 / 27)-3 \cdot \lambda \cdot x \cdot w_{-}(8 / 27)$ from investing amount $x$ into the risky lottery for three periods. In this case, the individual is indifferent between investing and not investing if and only if his or her index of loss aversion is

$$
\lambda=\frac{3.5 w_{+}(1 / 27)+3.5 w_{+}(7 / 27)+0.5 w_{+}(19 / 27)}{3 w_{-}(8 / 27)}
$$

Tables I and II demonstrate that in the experiments of Gneezy and Potters [1997] and Haigh and List [2005] the majority of subjects invest an intermediate fraction (1\%-99\%) of their initial endowment into the risky lottery. Such behavior is observed both in treatment $\mathrm{H}$ and treatment $\mathrm{L}$. The interpretation of this behavior is that the majority of subjects are exactly indifferent between investing and not investing in two treatments. Therefore, for the majority of subjects equations (1) and (2) should hold simultaneously. It turns out that for the typical parameterization of cumulative prospect theory equations (1) and (2) can indeed hold simultaneously. Probability weighting function for gains $w_{+}:[0,1] \rightarrow[0,1]$ is characterized by one parameter $\gamma \in(0,1)$. Similarly, probability weighting function for losses $w_{-}:[0,1] \rightarrow[0,1]$ is also characterized by one parameter $\delta \in(0,1)$. Therefore, for every value of $\gamma$ we can find a corresponding value of $\delta$ (and vice versa) such that the right hand side of equations (1) equals to the right hand side of equation (2). This correspondence is presented on Figure I by a solid line with squares. The horizontal axis measures the probability weighing coefficient for gains $\gamma \in[0.5,1]$. 
The vertical axis on the right hand side of Figure I measures the probability weighing coefficient for losses $\delta$. The points on the solid line with squares represent all pairs of coefficients $(\gamma, \delta)$ such that if an individual is indifferent between investing and not investing in one period, he or she is also indifferent between investing and not investing in three periods.

\section{[Insert Figure I here]}

The solid line on Figure I shows the value of the index of loss aversion $\lambda$, which is required to make an individual indifferent between investing and not investing (for a given $\gamma$ ). The index of loss aversion is measured on the vertical axis on the left hand side of Figure I. For example, consider an individual who has the probability weighing coefficient for gains $\gamma=0.6$. This individual is indifferent between investing and not investing both in one period and in three periods if the probability weighing coefficient for losses is $\delta=0.5$ and the index of loss aversion is $\lambda=2.0$. If $\gamma=0.6$, $\delta=0.5$ and $\lambda<2.0$, the individual invests $100 \%$ of the initial endowment both in one and in three periods. If $\gamma=0.6, \delta=0.5$ and $\lambda>2.0$, the individual invests nothing both in one and in three periods. If $\gamma=0.6, \lambda=2.0$ and $\delta>0.5$ the individual invests nothing in one period and everything — in three periods (MLA effect prevails). If $\gamma=0.6$, $\lambda=2.0$ and $\delta<0.5$ the individual invests everything in one period and nothing - in three periods (the effect of non-linear probability weighting prevails).

When MLA is combined with non-linear probability weighting, we can explain the results documented in Tables I and II without assuming any differences in the index of loss aversion across two treatments. Apparently, the effect of MLA is largely neutralized by the overweighting of small probabilities and the underweighting of 
moderate and high probabilities. Remarkably, for conventional parameterizations of cumulative prospect theory, the two effects exactly balance each other out. We already established that an individual with parameters $\gamma=0.6, \delta=0.5$ and $\lambda=2.0$ is exactly indifferent between investing and not investing both in treatment $\mathrm{H}$ and treatment $\mathrm{L}$. These parameters are very close to the best-fitting parameters $\gamma=0.61, \delta=0.69$ and $\lambda=2.25$ estimated by Tversky and Kahneman [1992] for cumulative prospect theory. This coincidence may explain why the majority of subjects happened to be exactly indifferent between investing and not investing both in treatment $\mathrm{H}$ and treatment $\mathrm{L}$.

In the analysis without probability distortions presented in the previous section, we concluded that the majority of subjects have the index of loss aversion $\lambda=1.25-1.56$. This estimate is lower than the conventional values of $\lambda=2.0-2.5$ found in numerous experiments [Kahneman et al., 1990]. When non-linear probability weighting is taken into account, the index of loss aversion inferred from the experiments on MLA is comparable to the conventional values found in other experiments.

\section{Samuelson's example}

The effects of MLA and non-linear probability weighing are well illustrated by a famous example due to Samuelson [1963]. Samuelson offered a colleague to bet $\$ 200$ to $\$ 100$ on a toss of a fair coin. The colleague rejected this lottery, but at the same time he was willing to accept 100 such bets. Samuelson [1963] proved a theorem that such a preference is inconsistent with expected utility maximization if a single lottery is rejected at every relevant wealth position. Benartzi and Thaler [1995] showed that the preference of Samuelson's colleague is consistent with MLA. Kahneman and Lovallo [1993] presented a similar argument. In fact, Samuelson's friend explained his preference with 
the following rationale: "I won't bet because I would feel the $\$ 100$ loss more than the $\$ 200$ gain. ... But in a hundred tosses of a coin, ... I am, so to speak, virtually sure to come out ahead in such a sequence, and this is why I accept the sequence while rejecting the single toss" [Samuelson, 1963].

The explanation of Samuelson's colleague is exactly the intuition behind the concept of loss aversion. A simple utility function that captures loss aversion is $u(x)=x$ if $x \geq 0$ and $u(x)=\lambda x$ if $x<0$ [Benartzi and Thaler, 1995; Thaler et al., 1997]. Figure II demonstrates the minimum index of loss aversion $\lambda$ that is required for an individual with this utility function to turn down a sequence of $n \in[1,100]$ Samuelson's lotteries. A solid line on Figure II demonstrates this minimum index of loss aversion (measured on the left vertical axis) when an individual does not distort probabilities. For example, an individual with the index of loss aversion $\lambda=2.25$ turns down the offer to bet on one toss but accepts the offer to bet on $n \in[2,100]$ tosses of a fair coin. Since the solid line increases exponentially, very high loss aversion $(\lambda=32888)$ is required to avert an individual from accepting a sequence of 100 Samuelson's lotteries.

The solid line with squares on Figure II demonstrates the minimum index of loss aversion (measured on the right vertical axis) that is required for an individual to turn down a sequence of $n \in[1,100]$ Samuelson's lotteries when he or she distorts probabilities in choice under risk. We model probability distortions by means of cumulative prospect theory with probability weighting functions $\quad w_{+}(p)=\exp \left\{-(-\ln p)^{\gamma}\right\} \quad$ and $w_{-}(p)=\exp \left\{-(-\ln p)^{\delta}\right\}$ proposed by Prelec [1998]. We do not use the functional form 
of a probability weighting function proposed by Tversky and Kahneman [1992] because it is not monotone for low values of parameters $\gamma$ and $\delta$.

The solid line with squares on Figure II is constructed for parameters $\gamma=0.6$ and $\delta=0.1$ (the situation without probability distortions corresponds to the case when $\gamma=\delta=1$ ). When probabilities are perceived non-linearly, the effect of MLA can be reversed. For example, an individual with the index of loss aversion $\lambda=2.25$ accepts the offer to bet on one toss but turns down the offer to bet on $n \in[2,100]$ tosses of a fair coin. This example directly contradicts to Langer and Weber [2005], who claim that such a preference is not possible for Samuelson's lottery even if probability weighting is taken into account [Langer and Weber, 2005, p.29]. Apparently, the effect of MLA can be completely offset by the effect of probability distortions. In particular, Figure II demonstrates that the effect of MLA is dominated when an individual severely distorts the probability of losses. A coefficient $\delta=0.1$ is close to zero, which implies that a probability weighting function for losses resembles a step function [Prelec, 1998].

Samuelson's example can be also used to illustrate that, depending on the index of loss aversion and the curvature of probability weighting functions, the combined effect of MLA and probability distortions can become non-linear. For example, the solid line with squares on Figure II shows that an individual with the index of loss aversion $\lambda=1.85(\gamma=0.6$ and $\delta=0.1$ as before) accepts the offer to bet on $n \leq 5$ and $n \geq 60$ tosses of a fair coin. However, this individual rejects the sequence of $n \in[6,59]$ Samuelson's lotteries. 


\section{Conclusion}

This paper uses the experimental data from Gneezy and Potters [1997] and Haigh and List [2005] to compare and contrast the impact of MLA in choice under risk with that of non-linear probability weighting. A close reexamination of the data suggests that myopic loss aversion cannot fully explain the experimental results. To do so, it is necessary to assume the systematic differences in the index of loss aversion of a modal subject across treatments with high and low evaluation frequencies. The paper shows that the distortions in probability weighting might significantly undermine the effects of MLA. Non-linear probability weighting in conjunction with MLA provides a complete explanation of experimental data. The paper extends the theoretical analysis of choice under risk by drawing a direct link between MLA and non-linear probability weighting, which can be further verified empirically.

Benartzi and Thaler [1995] discovered that loss aversion is the main component of prospect theory that helps to explain the equity premium puzzle. When Benartzi and Thaler [1995] replaced non-linear probability weights with actual objective probabilities, the qualitative results of their simulations did not change. In particular, the length of the evaluation period, which is required to make investors indifferent between investing in bonds and stocks, has fallen from 11-12 month to 10 month. This change denotes a slightly increased effect of MLA. Therefore, in the simulations of Benartzi and Thaler [1995], non-linear probability weighting offsets only a fraction of the effect of MLA. We demonstrate that this conclusion does not apply to the experimental results of Gneezy and Potters [1997] and Haigh and List [2005]. In particular, we find that the effect of nonlinear probability weighting exactly counterbalances the effect of MLA for conventional parameterizations of cumulative prospect theory. It remains to further research to 
investigate what drives this difference in results between macroeconomic simulations and microeconomic experiments.

\section{$\underline{\text { References }}$}

Abdellaoui, Mohammed, "Parameter-free Elicitation of Utility and Probability Weighting Functions”, Management Science, XLVI (2000), 1497-1512

Benartzi, Shlomo, and Richard Thaler, "Myopic Loss Aversion and the Equity Premium Puzzle”, Quarterly Journal of Economics, CX (1995), 73-95

Bleichrodt, Han, and Jose Pinto, "A Parameter-free Elicitation of the Probability Weighting Function in Medical Decision Analysis", Management Science, XLVI (2000), 1485-96

Gneezy, Uri, Arie Kapteyn, and Jan Potters, "Evaluation Periods and Asset Prices in a Market Experiment”, Journal of Finance, LXIII (2003), 821-38

Gneezy, Uri, and Jan Potters, “An Experiment on Risk Taking and Evaluation Periods", Quarterly Journal of Economics, CXII (1997), 631-45

Haigh, Michael, and John List, "Do Professional Traders Exhibit Myopic Loss Aversion? An Experimental Analysis", The Journal of Finance, LX (2005), 523-34

Harrison, Glenn, and John List, "Field Experiments", Journal of Economic Literature, XLII (2004), 1009-55

Kahneman, Daniel, Jack Knetsch, and Richard Thaler, "Experimental Tests of the Endowment Effect and the Coase theorem", Journal of Political Economy, XCVIII (1990), 1325-48

Kahneman, Daniel, and Amos Tversky, "Prospect Theory: An Analysis of Decision under Risk", Econometrica, XLVII (1979), 263-91 
Kahneman, Daniel, and Amos Tversky, "Choices Values and Frames", American Psychologist, XXXIX (1984), 341-50

Kahneman, Daniel, and Dan Lovallo, “Timid Choices and Bold Forecasts: A Cognitive Perspective on Risk Taking”, Management Science, XXXIX (1993), 17-31

Köbberling, Veronika, and Peter Wakker, "An Index of Loss Aversion“, Journal of Economic Theory, CXXII (2005), 119-31

Langer, Thomas, and Martin Weber, "Myopic Prospect Theory vs. Myopic Loss Aversion: How General is the Phenomenon?", Journal of Economic Behavior and Organization, LVI (2005), 25-38

Mehra, Rajnish, and Edward Prescott, "The Equity Premium: a Puzzle", Journal of Monetary Economics, XV (1984), 341-50

Prelec, Drazen, “The Probability Weighting Function”, Econometrica, LXVI (1998), $497-528$

Rabin, Matthew, "Risk Aversion and Expected Utility Theory: A Calibration Theorem", Econometrica, LXVIII (2000), 1281-92

Samuelson, Paul, "Risk and Uncertainty: A Fallacy of Large numbers", Scientia, XCVIII (1963), 108-13

Thaler, Richard, Amos Tversky, Daniel Kahneman, and Alan Schwartz, "The Effect of Myopia and Loss Aversion on Risk Taking: An Experimental Test“", Quarterly Journal of Economics, CXII (1997), 647-61

Tversky, Amos and Daniel Kahneman, “Advances in Prospect Theory: Cumulative Representation ofUncertainty", Journal of Risk and Uncertainty, V (1992), 297323 
Table I Classification of Subjects according to Investment

Strategy in Treatment $H$

\begin{tabular}{|l|c|c|c|}
\hline \multirow{2}{*}{$\begin{array}{c}\text { Classification of subjects according to } \\
\text { investment strategy }\end{array}$} & \multicolumn{3}{|c|}{ Percentage of subjects } \\
\cline { 2 - 4 } & $\begin{array}{c}\text { Gneezy and } \\
\text { Potters } \\
{[\mathbf{1 9 9 7 ]}}\end{array}$ & $\begin{array}{c}\text { Haigh and } \\
\text { List }[\mathbf{2 0 0 5} \text { students } \\
\text { studs }\end{array}$ & $\begin{array}{c}\text { Haigh and } \\
\text { List [2005], } \\
\text { professional } \\
\text { traders }\end{array}$ \\
\hline Invest $100 \%$ of endowment in all rounds & $12.2 \%$ & $6.3 \%$ & $11.1 \%$ \\
\hline $\begin{array}{l}\text { Invest } 100 \% \text { of endowment in the majority } \\
\text { of rounds } \geq 5 \text { rounds) }\end{array}$ & $4.9 \%$ & $9.4 \%$ & $11.1 \%$ \\
\hline Invest $1 \%-99 \%$ of endowment in all rounds & $43.9 \%$ & $53.1 \%$ & $25.9 \%$ \\
\hline $\begin{array}{l}\text { Invest } 1 \%-99 \% \text { of endowment in the } \\
\text { majority of rounds }(\geq 5 \text { rounds) }\end{array}$ & $21.9 \%$ & $25.0 \%$ & $37.1 \%$ \\
\hline Invest $0 \%$ of endowment in all rounds & $0.0 \%$ & $3.1 \%$ & $0.0 \%$ \\
\hline $\begin{array}{l}\text { Invest } 0 \% \text { of endowment in the majority of } \\
\text { rounds }(\geq 5 \text { rounds) }\end{array}$ & $9.8 \%$ & $0.0 \%$ & $7.4 \%$ \\
\hline Other & $7.3 \%$ & $3.1 \%$ & $7.4 \%$ \\
\hline
\end{tabular}


Table II Classification of Subjects according to Investment

Strategy in Treatment $L$

\begin{tabular}{|l|c|c|c|}
\hline \multirow{2}{*}{$\begin{array}{c}\text { Classification of subjects according to } \\
\text { investment strategy }\end{array}$} & $\begin{array}{c}|c| \\
\text { Gneezy and } \\
\text { Potters } \\
{[\mathbf{1 9 9 7 ]}}\end{array}$ & $\begin{array}{c}\text { Haigh and } \\
\text { List [2005], } \\
\text { students }\end{array}$ & $\begin{array}{c}\text { Haigh and } \\
\text { List [2005], } \\
\text { professional } \\
\text { traders }\end{array}$ \\
\hline Invest 100\% of endowment in all rounds & $33.3 \%$ & $12.5 \%$ & $25.9 \%$ \\
\hline $\begin{array}{l}\text { Invest } 100 \% \text { of endowment in the majority } \\
\text { of rounds ( } \geq 5 \text { rounds) }\end{array}$ & $2.4 \%$ & $6.3 \%$ & $11.1 \%$ \\
\hline Invest $1 \%-99 \%$ of endowment in all rounds & $45.2 \%$ & $65.6 \%$ & $51.9 \%$ \\
\hline $\begin{array}{l}\text { Invest } 1 \%-99 \% \text { of endowment in the } \\
\text { majority of rounds ( } \geq 5 \text { rounds) }\end{array}$ & $19.1 \%$ & $15.6 \%$ & $11.1 \%$ \\
\hline Invest $0 \%$ of endowment in all rounds & $0.0 \%$ & $0.0 \%$ & $0.0 \%$ \\
\hline $\begin{array}{l}\text { Invest } 0 \% \text { of endowment in the majority of } \\
\text { rounds ( } \geq 5 \text { rounds) }\end{array}$ & $0.0 \%$ & $0.0 \%$ & $0.0 \%$ \\
\hline
\end{tabular}




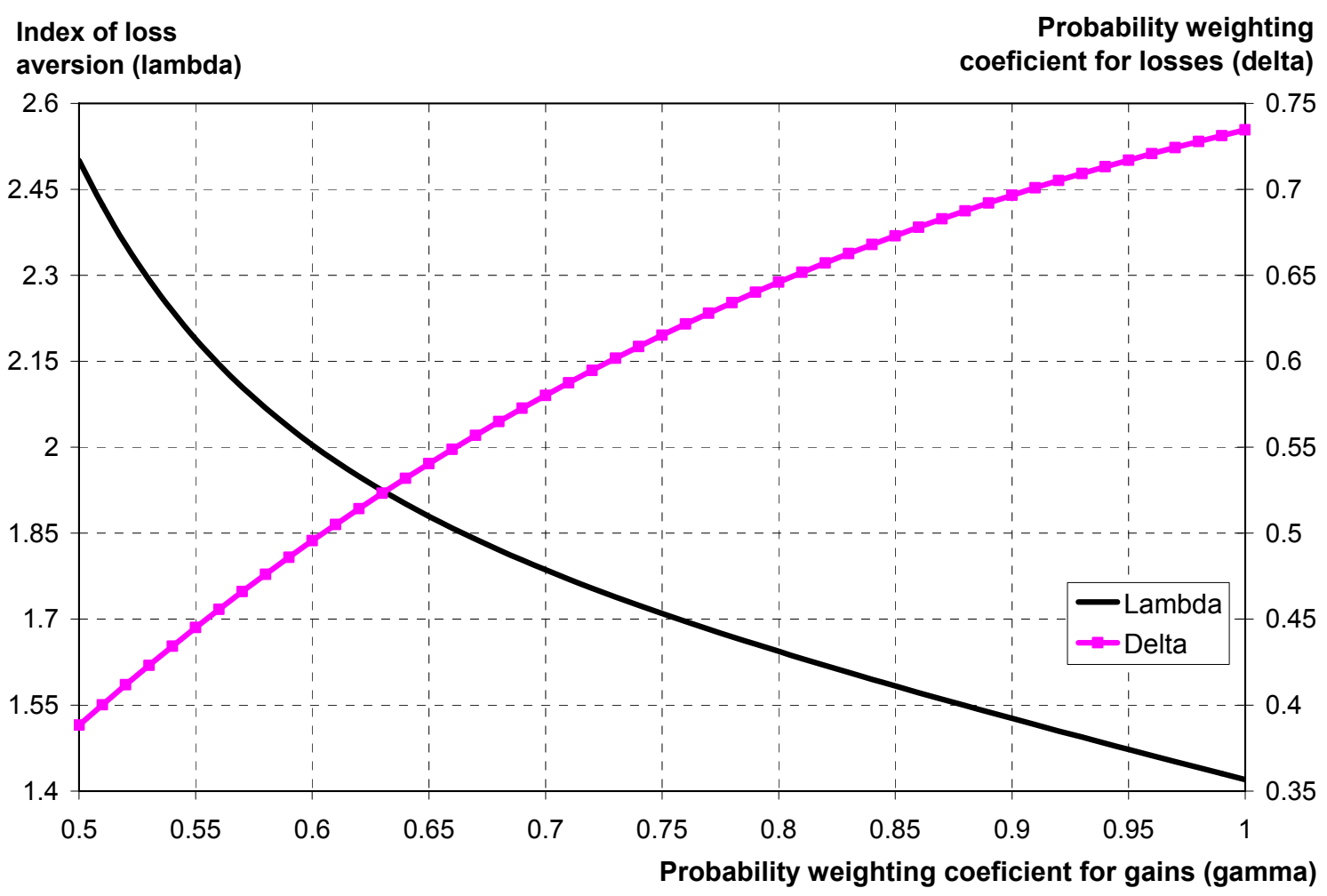

Figure I Parameterization of cumulative prospect theory, when an individual is indifferent between investing and not investing both in treatment $H$ and treatment $L$ 


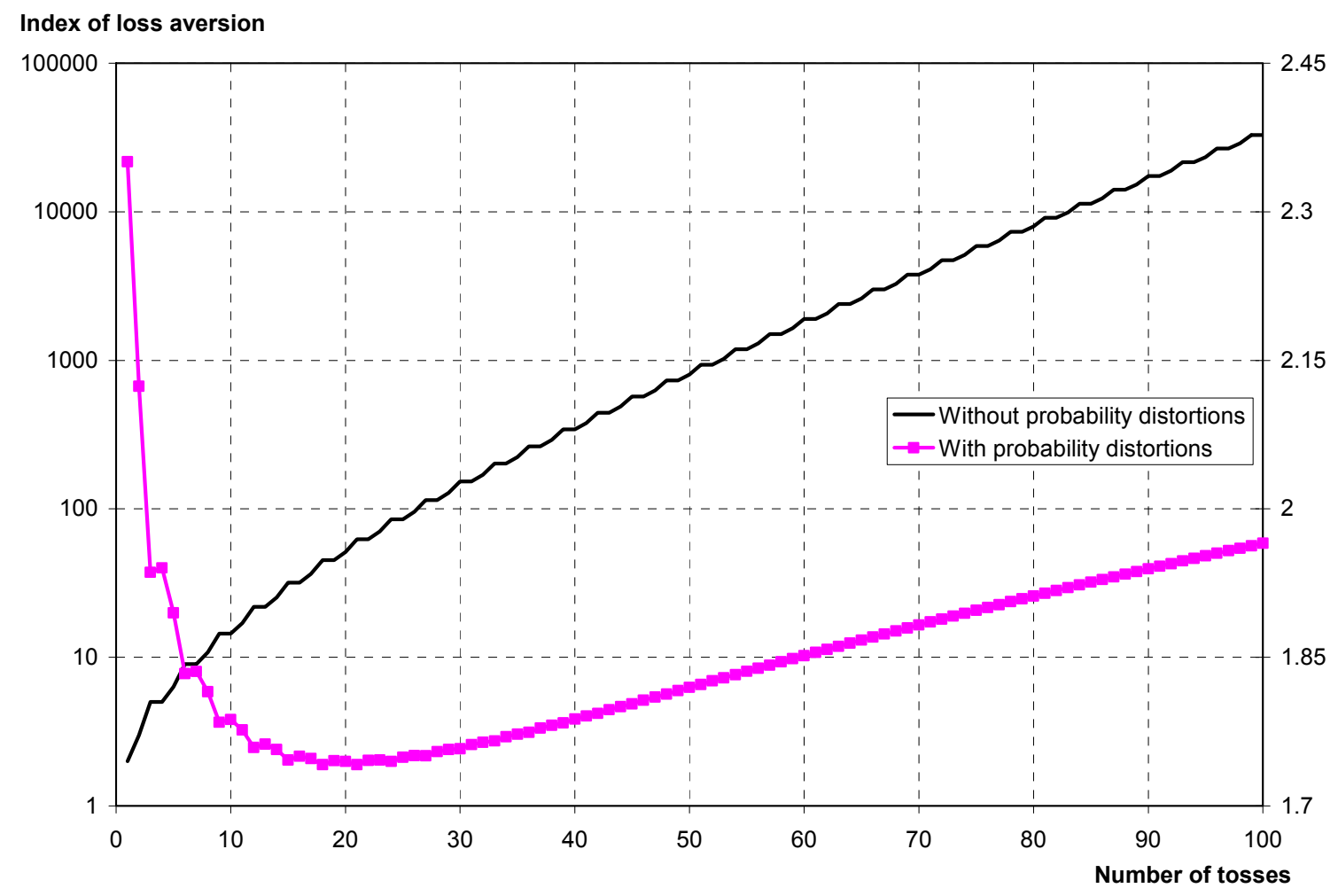

Figure II Minimum index of loss aversion that is required for an individual to turn down a sequence of Samuelson's lotteries 